EDITORIAL

\title{
A Educação e a Covid-19
}

Érika Dias a

Fátima Cunha Ferreira Pinto ${ }^{b}$

Ao ler os artigos que compõem o número 108 da Ensaio, além da diversidade de temas e análises, que são características do periódico, chamou a nossa atenção o primeiro texto, "A Covid-19 e a volta às aulas: ouvindo as evidências". No contexto atual, torna- se impossível não falar sobre a pandemia que assola o mundo, em virtude de tudo o que ela provocou e provoca, e da pergunta dos gestores, educadores, políticos e cidadãos: como será o mundo após a pandemia?

No que diz respeito à Educação, conforme a Organização das Nações Unidas para a Educação, a Ciência e a Cultura (Unesco), sabemos que a crise causada pela Covid-19 resultou no encerramento das aulas em escolas e em universidades, afetando mais de $90 \%$ dos estudantes do mundo (UNESCO, 2020). A partir desse número, pergunta-se: qual o futuro da Educação num mundo abalado pelo novo coronavírus?

Quando as escolas reabrirem, e, em algumas partes do mundo, tal evento já começou a ocorrer, a emergente recessão econômica, certamente, aumentará as desigualdades e poderá reverter o progresso obtido por alguns países na expansão do acesso educacional e na melhoria da aprendizagem. Por isso, é necessário que os países reconheçam o problema - como não o fizeram quando a COVID-19 começou a espalhar-se pelo mundo -, e criem políticas públicas voltadas especificamente para a Educação.

A nosso ver, por mais que a economia dos países sofra com a pandemia, os investimentos em Educação devem ser mantidos, quiçá aumentados. Conforme a Unesco, a natural queda na aprendizagem poderá alastrar-se por mais de uma década se não forem criadas políticas públicas que invistam em melhorias de infraestrutura, tecnologias, formação, metodologias e salários, além do reforço da merenda, melhor aproveitamento do tempo, tutoria fora do horário usual das aulas e material adicional, quando possível (UNESCO, 2020). Em concordância com a Unesco, o parecer do Conselho Nacional de Educação do Ministério da

\footnotetext{
a Fundação Cesgranrio, Rio de Janeiro, RJ, Brasil/ Universidade Nova de Lisboa, Lisboa, Portugal.

b Fundação Cesgranrio/ Academia Brasileira de Educação, Rio de Janeiro, RJ/ Academia Fluminense de Letras, Niterói, RJ, Brasil.
} 
Educação do Brasil, seguiu a mesma linha e reconheceu os problemas causados pela pandemia. O parecer procurou reorganizar as atividades acadêmicas e sinalizou com a permissão para aulas aos sábados - em horários de contraturno e durante as férias -, para que os alunos da Educação Básica não percam o ano letivo e apontou outras medidas semelhantes àquelas já defendidas pela Unesco (BRASIL, 2020).

A Educação a distância $(\mathrm{EaD})$ não pode ser a única solução, esta metodologia tende a exacerbar as desigualdades já existentes, que são parcialmente niveladas nos ambientes escolares, simplesmente, porque nem todos possuem o equipamento necessário. Se a meta for investir apenas em ferramentas digitais, certamente, contribuiremos para uma piora na aprendizagem dos alunos a curto e a médio prazos (SOUZA; FRANCO; COSTA, 2016).

Nós precisamos repensar o futuro da Educação, incluindo uma articulação apropriada entre o EaD e o Ensino presencial (UNESCO, 2020). Até porque, muitos no Brasil não têm acesso a computadores, celulares ou à Internet de qualidade - realidade constatada pelas secretarias de Educação de Estados e municípios no atual momento - e um número considerável alto de professores precisou aprender a utilizar as plataformas digitais, inserir atividades online, avaliar os estudantes a distância e produzir e inserir nas plataformas material que ajude o aluno a entender os conteúdos, além das usuais aulas gravadas e online. Na pandemia, grande parte das escolas e das universidades estão fazendo o possível para garantir o uso das ferramentas digitais, mas sem terem o tempo hábil para testá-las ou capacitar o corpo docente e técnico-administrativo para utilizá-las corretamente.

Há ainda outros obstáculos graves, especialmente para alunos e professores mais empobrecidos, muitos deles localizados na periferia das grandes cidades ou na zona rural. Faltam computadores, aparelhos de telefonia móvel, software e Internet de boa qualidade, recursos imprescindíveis para um EaD que resulte em aprendizagem.

Não podemos esquecer que saúde física e saúde mental andam juntas. A duração prolongada do confinamento, a falta de contato pessoal com os colegas de classe, o medo de ser infectado, a falta de espaço em casa - torna o estudante menos ativo fisicamente do que se estivesse na escola -, e a falta de merenda para os alunos menos privilegiados são fatores de estresse que atingem a saúde mental de boa parte dos estudantes da Educação Básica e das suas famílias. Estimular a solidariedade, a resiliência e a continuidade das relações sociais entre educadores 
e alunos nesse período é fundamental, pois ajuda a minorar o impacto psicológico negativo da pandemia nos estudantes. Agora, importa prevenir e reduzir os níveis elevados de ansiedade, de depressão e de estresse que o confinamento provoca nos estudantes em quarentena (MAIA; DIAS, 2020).

No momento atual, muitas escolas, públicas e privadas, estão exagerando nas expectativas do que professores e familiares conseguem fazer. Há diferenças substanciais entre as famílias, atualmente, em confinamento. Algumas podem ajudar seus filhos a aprender mais do que outras. Fatores como a quantidade de tempo disponível para se dedicar aos estudos dos filhos, auxiliando-os com as aulas online - muitos pais estão em home office cumprindo horário laboral integral e outros tantos precisam trabalhar externamente para garantir a renda mensal -; as habilidades não cognitivas dos genitores; a possibilidade de acessar o material online; a quantidade de conhecimento inato dos pais - afinal, é difícil ajudar o filho se tiver de aprender algo estranho ao que se conheceu e aprendeu -, são questões a serem levados em conta quanto ao papel dos pais na Educação dos filhos em tempos de pandemia. Toda essa situação gerará um aumento da desigualdade na Educação e no progresso do estudante (CIFUENTES-FAURA, 2020).

Além disso, os secretários de Educação e os gestores das escolas precisam pensar na saúde mental de todos, até porque, os professores também estão fragilizados. Se os educadores ficarem exaustos mentalmente, e aproximaremse de um esgotamento físico e mental, não poderão ajudar a si ou aos alunos (MAIA; DIAS, 2020).

Para construirmos um futuro mais saudável, próspero e seguro, precisamos de políticas públicas que garantam um financiamento adequado para a Educação, fazer uso inteligente das tecnologias disponíveis, priorizar os mais vulneráveis e proteger educadores e alunos. O Estado precisa se fazer presente.

Feita esta reflexão, voltamos nossa atenção para os textos que compõem este número da Ensaio. Os artigos ora publicados, se orientaram por essa premissa para um futuro melhor. Autores brasileiros e estrangeiros discutiram uma gama variada de temas, passando pela pandemia provocada pelo novo Coronavírus, a Educação especial, o cuidado com grupos minoritários, a formação de uma cultura de paz nos estudantes da Educação Básica, as mudanças implementadas recentemente no Ensino Médio e a diferença de gênero no ambiente escolar. Temáticas distintas que apresentam um amálgama que as une, que é o objetivo de garantir uma Educação mais inclusiva, para todos. 
Inauguramos o número 108 da Ensaio com o artigo que discute um tema atual: como melhorar a aprendizagem dos alunos quando a pandemia passar? A questão traz à tona um importante assunto: o retorno ao ambiente escolar.

No texto "A Covid-19 e a volta às aulas: ouvindo as evidências", João Oliveira, Matheus Gomes e Thais Barcellos analisam a questão da paralisação prolongada por causa da quarentena imposta pela pandemia, o impacto das tecnologias no desempenho escolar e quais os caminhos mais promissores para que este não seja um ano completamente perdido para os alunos da Educação Básica.

$\mathrm{O}$ artigo seguinte, "A Lei $\mathrm{n}^{\circ} 13.415$ e as alterações na carga horária e no currículo do Ensino Médio", de Paulo Romualdo Hernandes, analisou a reforma do Ensino Médio, efetivada com a Lei ${ }^{\circ}$ 13.415. O autor estudou o conteúdo da lei, a partir dos pressupostos da Pedagogia Histórico-Crítica, que defende que a escola precisa promover o Ensino e a aprendizagem de conhecimentos complexos e sistematizados, pois, além de espaço de saber, a escola tem uma razão de ser, e esta é social. O estudo indicou que a ampliação da carga horária e as inovações curriculares são importantes, mas sem política de financiamento para as escolas públicas realizarem as alterações previstas na lei, nomeadamente para a contratação, remuneração e melhores condições de trabalho para os docentes, dificilmente poderá ter os resultados esperados, que era, a princípio, adequar o Ensino Médio do Brasil aos dos países da Organização para Cooperação e Desenvolvimento Econômico (OCDE).

$\mathrm{O}$ terceiro artigo "Multiple imputation in big identifiable data for Educational research: An example from the Brazilian Education assessment system", uma colaboração luso-brasileira, das autoras Maria Eugénia Ferrão, Paula Prata e Maria Tereza Gonzaga Alves, analisou os dados da Prova Brasil 2017. Com o objetivo central de esclarecer o porquê dos estudos quantitativos em aferição, da avaliação e da pesquisa educacional serem baseados em conjuntos de dados incompletos. As autoras procuraram fornecer informações sobre a verificação da falta de padrão e os procedimentos de dados ausentes para cientistas sociais propensos a usar software de acesso aberto, e demonstraram que a maior parte do conhecimento acumulado sobre o tema equidade social, e assuntos relacionados, pode ser seriamente comprometida se for baseada em suposições ingênuas de dados ausentes.

O artigo seguinte vem do Norte do Brasil e intitula-se "Deficiência visual: caminhos legais e teóricos da escola inclusiva". Nele, Fabiane Maia Garcia e Aissa Thamy Alencar Mendes Braz, da Universidade Federal do Amazonas, apresentaram os 
resultados de uma pesquisa sobre a cegueira, a baixa visão e a acessibilidade dos alunos, registrados no Sistema Eletrônico do Serviço de Informação ao Cidadão (e-SIC) com deficiência visual, às escolas de Manaus. As autoras, ao longo do estudo, compreenderam que a rede municipal de Ensino em Manaus ainda não conseguiu assegurar, para esses alunos, o acesso às escolas inclusivas ou escolas exclusivas e o atendimento educacional especializado, pois a grande parte das escolas não oferece acessibilidade. As autoras esperam que o estudo colabore para a efetivação de uma ação educativa inclusiva.

Da Espanha, temos o artigo "La respuesta educativa a los alumnos más capaces en los planes de atención a la diversidade", de Lorenzo Pérez Diez e de Carmen Jimenez Fernandez, ambos da Universidad Nacional de Educación a Distância, em Madri. Nele, os autores discutiram a questão da diversidade e os procedimentos criados para grupos minoritários. Como o sistema educativo espanhol tem, por meio do Plano de Atenção à Diversidade, planificado, implementado e avaliado medidas para diferentes grupos, com necessidades distintas, porém, sem darem muita atenção para um grupo específico, o dos alunos superdotados. A partir de uma pesquisa feita nas escolas da província de Palencia, na Comunidade Autónoma de Castela e Leão, os autores perceberam que a presença de medidas educativas destinadas a esses alunos é nula ou puramente testemunhal, sendo necessário que tais medidas sejam efetivamente postas em prática, tal como está estabelecido no Plano educacional espanhol.

O sexto artigo, "Youth leadership and global citizenship: alternatives for peacebuilding in Brazilian public schools", uma colaboração de professores da Universidade Católica de Brasília e da Universidade de Alberta no Canadá Geraldo Caliman, Ranilce Guimaraes-Iosif, Jose Ivaldo A. de Lucena e Vanildes Gonçalves dos Santos -, discutiu uma temática cada vez mais relevante: uma Educação para paz, uma Educação focada na redução da violência no contexto das escolas. Fizeram essa discussão a partir do pressuposto de que a Universidade e a escola, enquanto espaços de Educação formal, têm um grande potencial como promotores e construtores da paz. A pesquisa foi feita em duas escolas públicas do Distrito Federal, com alunos do Ensino Médio, analisando o contexto da juventude atual, a percepção que os jovens têm sobre a cidadania e sobre a construção da paz. Analisaram o papel da universidade e da escola pública na construção de redes que atuam proativamente na Educação dos jovens para a cidadania, preparando-os para o eventual confronto com situações de violência e intolerância e demonstraram como as experiências de sucesso foram capazes de ativar a prevenção da violência escolar e auxiliar no processo de construção de uma cidadania global. 
Em seguida, temos uma contribuição do Nordeste, os autores Renata Meira Veras, Wilton Nascimento Figueredo, Sayuri Miranda de Andrade Kuratani e Erika Silva Chaves, todos de Universidades públicas da Bahia, escreveram sobre a "Formação de Professores na Universidade Federal da Bahia: análise das licenciaturas noturnas". Na pesquisa feita, os autores analisaram a carga horária e os componentes curriculares da formação docente nos cursos de licenciatura noturnos da Federal da Bahia. A estrutura curricular encontrada nesse estudo evidenciou a falta de inovações e avanços na quantidade de disciplinas e nas cargas horárias que priorizavam a formação docente. Essas, deveriam habilitar o licenciando a desempenhar uma carreira docente com uma base consistente da prática escolar. Os autores fizeram uma pesquisa documental, com dados oficiais, mas sentiram falta de ouvir os licenciandos e egressos acerca da sua formação, ficando tal estudo para um segundo momento.

Da Universidade ORT do Uruguai, recebemos o artigo "Uso de plataformas y herramientas digitales para la Enseñanza de la Matemática" escrito pelos autores Denise Vaillant, Eduardo Rodríguez Zidán e Gustavo Bentancor Biagas. Os pesquisadores investigaram o uso de ferramentas e de plataformas digitais para o Ensino da Matemática no $1^{\circ}$ ano da Educação Secundária do Uruguai. Entre os resultados, destacaram a baixa frequência no uso de ferramentas e plataformas digitais por parte dos professores. Além disso, os resultados indicam que os smartphones são os dispositivos mais utilizados pelos professores para o Ensino e que há preferências no uso de aplicativos. A idade dos professores não foi um fator que influenciou no uso das tecnologias pelos docentes, contudo, possuir um diploma de pedagogia para o nível em que atuavam e a experiência profissional como docentes do Ensino Médio foram elementos que contribuíram para aumentar a eficácia do uso das tecnologias de informação e comunicação (TIC) no Ensino Básico.

Da Universidade de Málaga na Espanha, chega-nos o artigo "Gender differences in school performance and attitudes toward school", de Carmen Rodríguez Martínez e Monsalud Gallardo Gil. Os pesquisadores estudaram as diferenças de gênero no desempenho escolar e nas atitudes de moças e de rapazes em relação à escola. Para tal, utilizaram dados das avaliações nacionais da Espanha e internacionais (OCDE) a fim de compreender as percepções dos estudantes que continuaram os estudos, com sucesso, indo até o Ensino Superior. Com o trabalho, os autores descobriram que os arquétipos sociais em torno da divisão sexual tradicional do trabalho, de acordo com os papéis estabelecidos por gênero, parecem reforçar a insatisfação de um número maior de rapazes em relação à escola. Por outro lado, as atitudes mais positivas das meninas em relação aos estudos e seu envolvimento 
na escola servem, como mostram os relatórios internacionais da OCDE e a pesquisa deles, para promover seu sucesso nas instituições de Ensino.

O décimo artigo vem da Universidade Federal de Santa Catarina, da autoria dos professores Diego Eller Gomes, Marina Bazzo de Espíndola, Roberto Moraes Cruz e Dalton Francisco de Andrade. O objetivo da pesquisa, intitulada "Efetividade da formação profissional ofertada na Educação a distância: validação teórica de um instrumento" foi autenticar um instrumento de avaliação que atestasse a efetividade em cursos na modalidade de EaD. Para isso, utilizaram a técnica Delphi, para validação de escalas e questionários a partir da opinião de especialistas. A possibilidade de aplicação dessa técnica de forma online permitiu maior rapidez e a inclusão de especialistas de diversas regiões do Brasil. Contudo, os autores afirmam que ainda é necessária uma aplicação futura de análises estatísticas. Essas análises possibilitarão a construção de uma escala de efetividade da formação profissional em cursos na modalidade $\mathrm{EaD}$, de modo que se compreenda em que medida, determinado curso foi efetivo, e o que mais pode ser aprimorado.

O décimo primeiro artigo, intitulado "El papel de la internacionalización de la Educación Superior en la producción científica brasileña", é mais uma colaboração da Espanha. As pesquisadoras Cláudia Daniele de Souza, Daniela De Filippo e o professor catedrático Elías Sanz Casado, todos da Universidade Carlos III de Madrid, analisaram a internacionalização do Ensino Superior no Brasil entre os anos 2000-2015. Fundamentaram o estudo em publicações científicas indexadas em bases de dados internacionais com foco na colaboração internacional. Através de uma abordagem bibliométrica, os autores obtiveram a evolução da produção em colaboração e sua relação com impacto e visibilidade. Os resultados mostram que a produção em colaboração teve oscilações, mas o número de citações recebidas e o quartil dos periódicos de publicação melhoraram consideravelmente com a colaboração internacional. Os principais colaboradores são países beneficiários de estudantes e pesquisadores que participaram de programas de mobilidade internacional, incluindo o Ciência sem Fronteiras do Brasil.

A fechar a revista, na seção Página Aberta, apresentamos o artigo "Cenários da Educação de mulheres jovens e adultas em situação de privação de liberdade no contexto brasileiro", nele, as professoras da Universidade do Vale do Rio DoceMG, Maria Celeste Reis Fernandes de Souza, Eunice Maria Nazareth Nonato e Maria da Conceição Ferreira Reis Fonseca, discutiram a questão da Educação escolar para mulheres aprisionadas. Apesar de estar previsto nos Planos Estaduais de Educação dos estados da Federação e os resultados indicarem avanços no 
campo legal, apontam que há um longo caminho a ser percorrido para garantir o direito à Educação na prisão, especialmente para mulheres. As autoras ressaltam a necessidade de se pensar em um processo que torne essas mulheres visíveis e merecedoras de alcançarem um saber formal.

Os doze artigos aqui publicados, refletem uma grande variedade temática e demonstram que a Educação continua a ser uma ferramenta para a transformação da sociedade. A leitura de artigos tão distintos, oriundos de diversas partes do Brasil, Portugal, Espanha e Uruguai fará o leitor refletir sobre a nova normalidade que nos aguarda após a pandemia e como é importante garantir uma Educação voltada para todos, e para tal, é essencial reforçar a pesquisa e a ciência (FREIRE, 2002).

Se acreditamos que a Educação exerce forte influência nas transformações da sociedade, então, acreditamos que a Educação reforça a capacidade crítica do indivíduo e atesta o grau de desenvolvimento desta mesma sociedade (DIAS; PINTO, 2019). A nosso ver, com inteligência, integridade, competência e planejamento, podemos aprender com essa crise e, futuramente, transformar a sociedade, formar cidadãos conscientes, e melhorar a Educação no Brasil e no mundo.

Boa leitura a todos. 


\section{Referências}

BRASIL. Ministério da Educação. Conselho Nacional da Educação. Parecer CNE/CP No 5/2020. Reorganização do Calendário Escolar e da possibilidade de cômputo de atividades não presenciais para fins de cumprimento da carga horária mínima anual, em razão da Pandemia da COVID-19. Diário Oficial da União, Brasília, DF, 1 jun. 2020.

CIFUENTES-FAURA, J. Consecuencias en los niños del cierre de escuelas por Covid-19: el papel del gobierno, profesores y padres. Revista Internacional de Educación para la Justicia Social, Madrid, v. 9, n. 3e, p. 1-12, 2020. Disponível em: https://revistas.uam.es/riejs/article/ view/12216/12089. Acesso em: 4 jun. 2020

DIAS, E.; PINTO, F. C. F. Educação e sociedade. Ensaio: Avaliação e Políticas Públicas em Educação, Rio de Janeiro, v. 27, n. 104, p. 449-454, set. 2019. https://doi.org/10.1590/s0104-40362019002701041

FREIRE, P. Pedagogia da autonomia: saberes necessários à prática educativa. 25. ed. São Paulo: Paz e Terra, 2002

MAIA, B. R.; DIAS, P. C. Ansiedade, depressão e estresse em estudantes universitários: o impacto da COVID-19. Estudos de Psicologia (Campinas), Campinas, v. 37, e200067, 2020. https://doi.org/10.1590/1982$0275202037 \mathrm{e} 200067$

SOUZA, S.; FRANCO, V. S.; COSTA, M. L. F. Educação a distância na ótica discente. Educação e Pesquisa, São Paulo, v. 42, n. 1, p. 99-114, jan./mar. 2016. https://doi.org/10.1590/s1517-9702201603133875

UNESCO. A Comissão Futuros da Educação da Unesco apela ao planejamento antecipado contra o aumento das desigualdades após a COVID-19. Paris: Unesco, 16 abr. 2020. Disponível em: https://pt.unesco. org/news/comissao- futuros- da- educacao- da- unesco- apela- aoplanejamento- antecipado- o- aumento-das. Acesso em: 4 jun. 2020. 


\section{Informações das autoras}

Érika Dias: Doutora em História Moderna pela Universidade Nova de Lisboa. Editora da revista Ensaio: avaliação e políticas públicas em Educação. Pesquisadora correspondente do Centro de Humanidades da Universidade Nova de Lisboa. Contato: erikadias@ cesgranrio.org.br

iD https://orcid.org/0000-0002-5608-646X

Fátima Cunha Ferreira Pinto: Doutora em Filosofia, com Pós-Doutorado pela Universidad Nacional de Educación a Distância. Editora da revista Ensaio: avaliação e políticas públicas em Educação; assessora Especial da Presidência e dos Projetos Especiais da Fundação Cesgranrio; membro da Academia Brasileira de Educação e da Academia Fluminense de Letras. Contato: fatimacunha@cesgranrio.org.br

iD https://orcid.org/0000-0002-4461-8414 